\title{
The energy transition and where mobility will go to
}

\author{
ManfRed F. WAIDHAS \\ formerly Siemens AG - 91058 Erlangen, Germany
}

\begin{abstract}
Summary. - Enforced extension of renewable power will be required to achieve the targeted $\mathrm{CO}_{2}$ reduction. Hereby, it will be essential to shift renewable electricity to the mobility and industry sector. The transportation sector exhibits the highest need for action. Here the concept of the future will be electric. The main challenge will be the poor energy density of batteries compared to oil-based fuels. Trends and solutions for transportation via road, rail, sea and air are discussed in the paper.
\end{abstract}

The reduction of carbon dioxide is the environmental challenge of our current and the following generation. Related emissions are rated responsible for climate change and increasing number of extreme weather situations. Political efforts to establish a joint and harmonized route for related measures are emerging, however, only with marginal results. The sector with high relevance but also with lacking success in $\mathrm{CO}_{2}$ reduction is the mobility sector (fig. 1).

The reduction of greenhouse gases is clearly linked with renewables. Their enforced extension is mandatory to reach defined $\mathrm{CO}_{2}$ reduction targets. Related power generation is volatile and to a certain degree unpredictable. This is one of the major challenges of utilities and grid operators as power generation has to follow the power demand every second in order to keep grid frequency constant (mandatory!). In order to address the mismatch between power generation and demand (but also to prevent curtailment and shutdown of renewables) suitable storage concepts have to be implemented. 


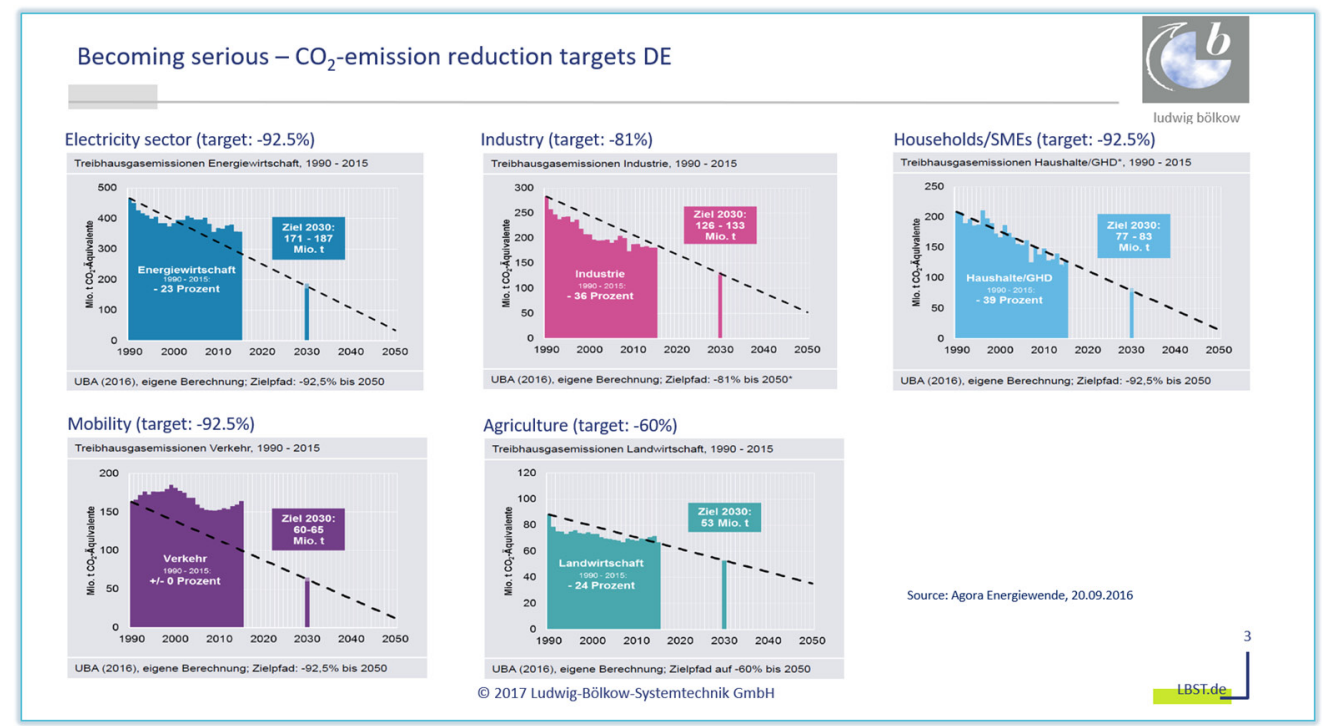

Fig. 1. $-\mathrm{CO}_{2}$ reduction in Germany: targets and progress. Source: LBST, Germany.

A variety of different energy storage concepts is known (fig. 2). Each of them has its specific strengths, but there is no universal solution for all applications. For example, small decentralized grid duties may be handled by batteries. However - for several reasons - storage capacities $>100 \mathrm{MW}$ (relevant for high-voltage transmission grids) can only be addressed by "Pumped Hydro", "Compressed Air" (CAES) and "Hydrogen".

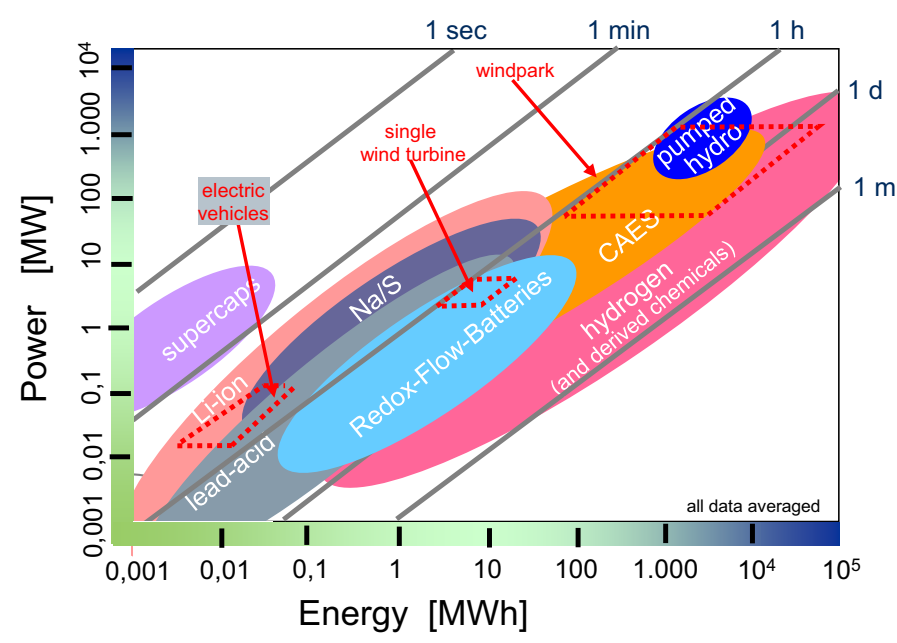

Fig. 2. - Segmentation of different electrical energy storage options. 


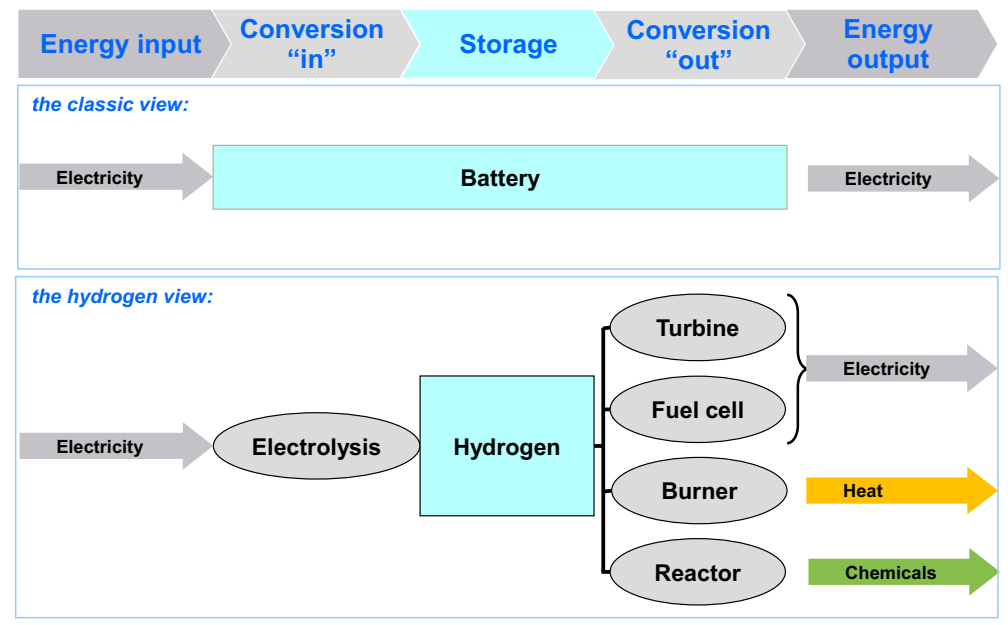

Fig. 3. - Principle of energy storage: hydrogen options vs. conventional battery storage.

Chemical energy storage, like hydrogen or derived chemicals are considered as the only approach to store electricity $>10 \mathrm{GWh}$. An outstanding property of hydrogen is its multi-functionality. The conventional understanding of electricity storage is based on a battery (electricity in/electricity out). In contrast to that hydrogen can be re-electrified in a gas turbine, combustion engine or a fuel cell but it can also be used directly in industry or used/converted to a fuel for transportation (fig. 3). This opens the very important ability to link the power sector with the mobility and industry sector ("sector coupling", fig. 4).

Hydrogen is a very important raw material for chemical industry. It is essential for fertilizer production, in refineries, steel production and many other branches. The worldwide demand is around 500 billion cubic meter per year, corresponding to a market of approximately 100 billion Euro. Main production route is via steam reforming of natural gas or coal with a corresponding $\mathrm{CO}_{2}$ footprint. The generation by electricity via electrolysis is - due to higher production costs - only a niche market for very remote areas or where extreme gas purity is needed.

However, the $\mathrm{H}_{2}$ production via electricity gets new attractiveness for the following reasons:

- the $\mathrm{CO}_{2}$ footprint is zero as long as green electricity is used;

- electricity (from the power sector) can be shifted to mobility and industry sector and used for frequency control;

- production costs are competitive to steam reforming when electricity costs are low.

These three arguments are essential preconditions to push forward the energy transition. In some regions of the world costs of green electricity are even below 2 Eur-ct 


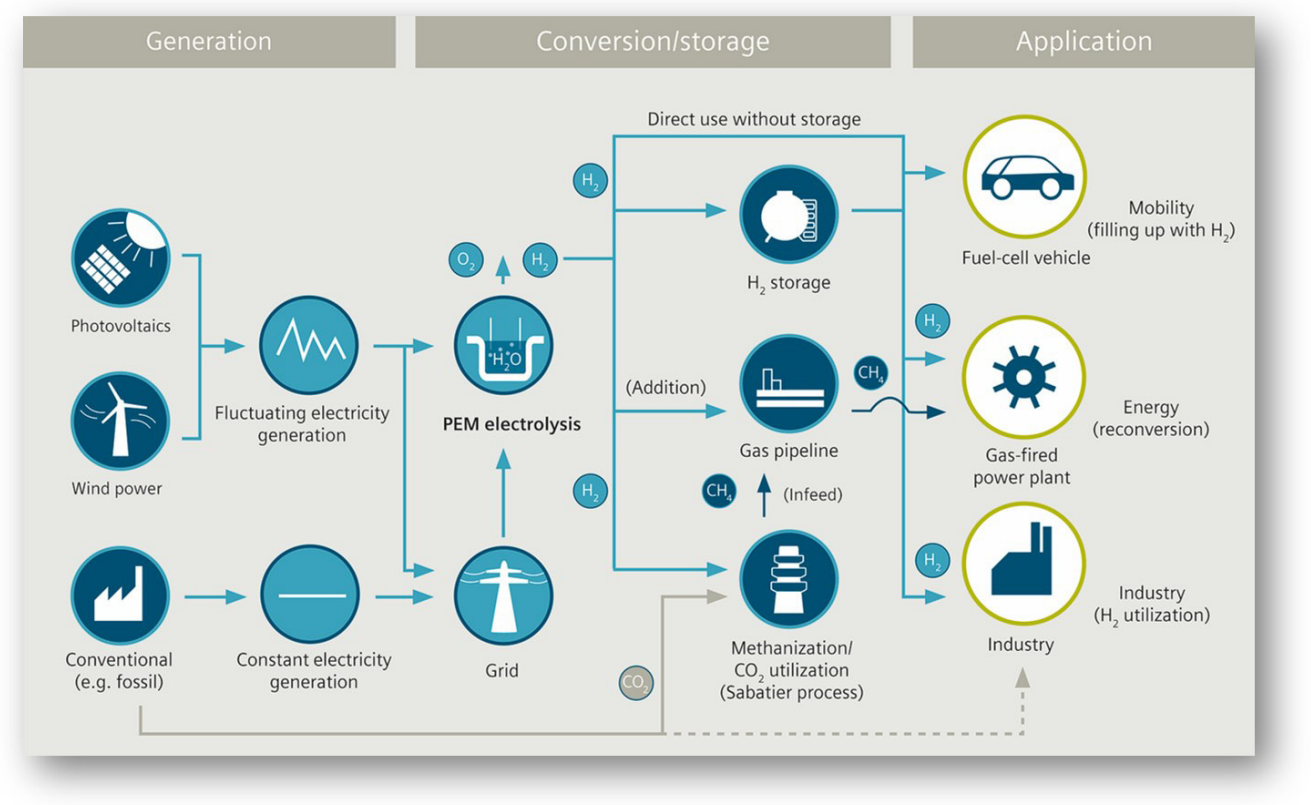

Fig. 4. - Different generation, storage and application routes of hydrogen.

per kWh. As a consequence, production costs of green hydrogen would be fully competitive with the $\mathrm{CO}_{2}$-loaded steam reforming process and will not require additional legal framework for regulation (fig. 5).

Hydrogen is usually stored as compressed gas. Depending on size and application it is done in cylinders (e.g., 700 bar for passenger cars), big steel vessels (20-100 bar) or in geological salt caverns (60-200 bar). Caverns with typical volumes of 100000 to
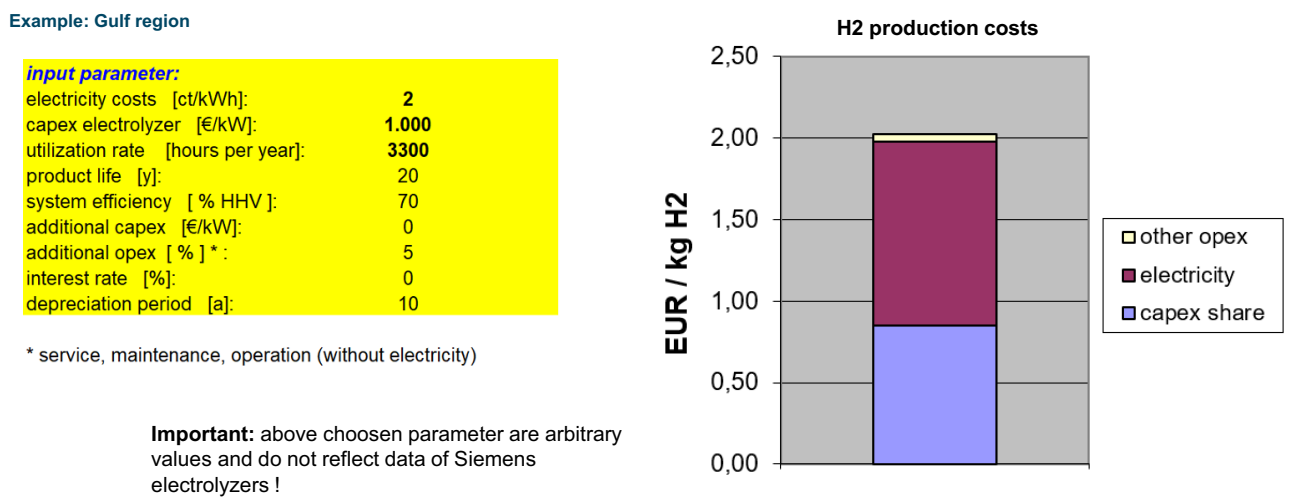

Fig. 5. - Production costs of hydrogen based on parameter relevant for the Gulf-region. 


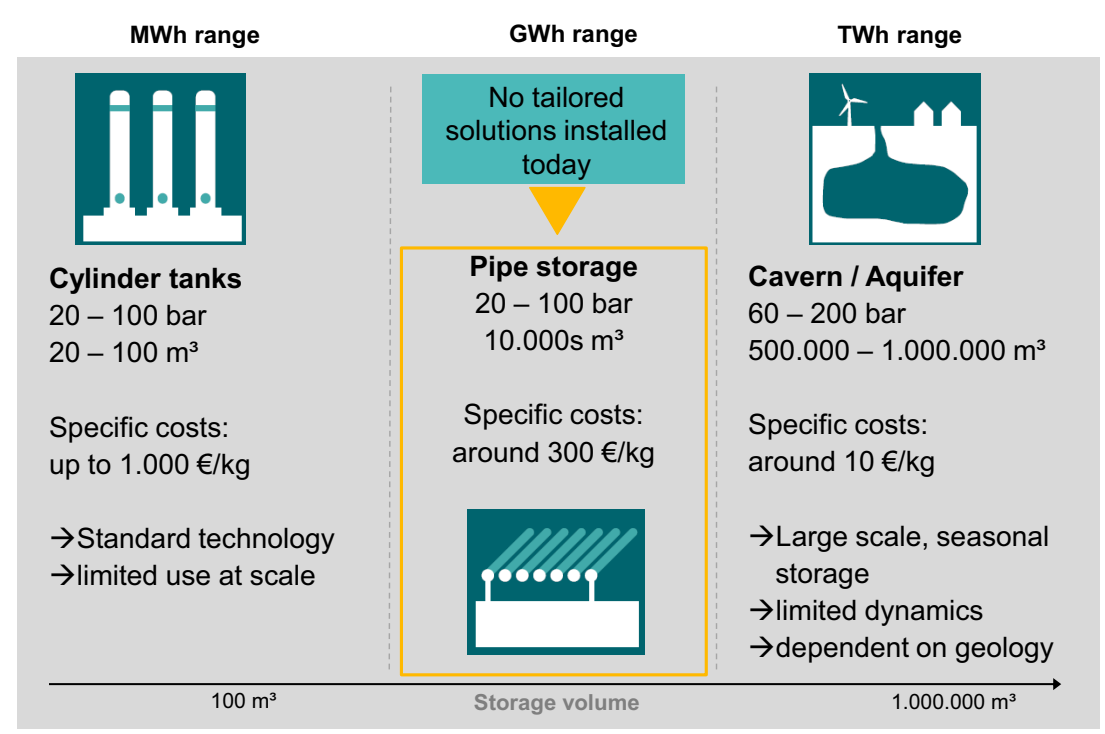

Fig. 6. - Large-scale storage options for hydrogen (source: T. Bielmeier, Siemens).

$500000 \mathrm{~m}^{3}$ enable energy storage in the TWh range (fig. 6). Additional methods of storage are via chemicals, e.g. in metal hydrides or organic liquids.

Hydrogen is also an interesting issue for countries with a high ratio of energy imports (like Japan). Generated via green electricity in regions with cheap renewable electricity it has to be transported to the place of use. Usually this is done as compressed gas in vessels (via trailer or ship) or in pipelines.

Long-distance transport is done cryogenic in the liquid phase (at $-253{ }^{\circ} \mathrm{C}$ ).

The link of hydrogen to fuels is of particular interest for transportation. The ideal route of course is the direct use of hydrogen. Due to its unusual properties (density $\approx 0.1 \mathrm{~kg} / \mathrm{l}$; boiling point: $-253^{\circ} \mathrm{C}$ ) it is not suited for all applications to store it onboard. In these cases the transformation to eFuels will be an option. They are liquids with tunable properties. So it will be viable to produce synthetic gasoline, diesel or kerosene.

Electrolyzers are the technological link between power generation, industry and mobility. The principle of water splitting (fig. 7) is known since the year 1800 but the first industrial utilization emerged slowly in the early 1900s. As already stated, its use was restricted to niches. Nowadays, by the concept of sector coupling there is a new interest in this technology. There are three basic types of electrolyzers: "alkaline", "solid oxid" and "PEM" - their name derived from the nature of the electrolyte.

Initial concepts did not consider sector coupling. Those aimed at pure electricity storage only and were based on re-electrification of generated and stored gas. The initial approach (1990s) was based on the injection of hydrogen into the existing natural gas grid. By this concept re-electrification could be performed with conventional gas turbines as they tolerate admixing of hydrogen to a certain degree. The limiting factor is the high 

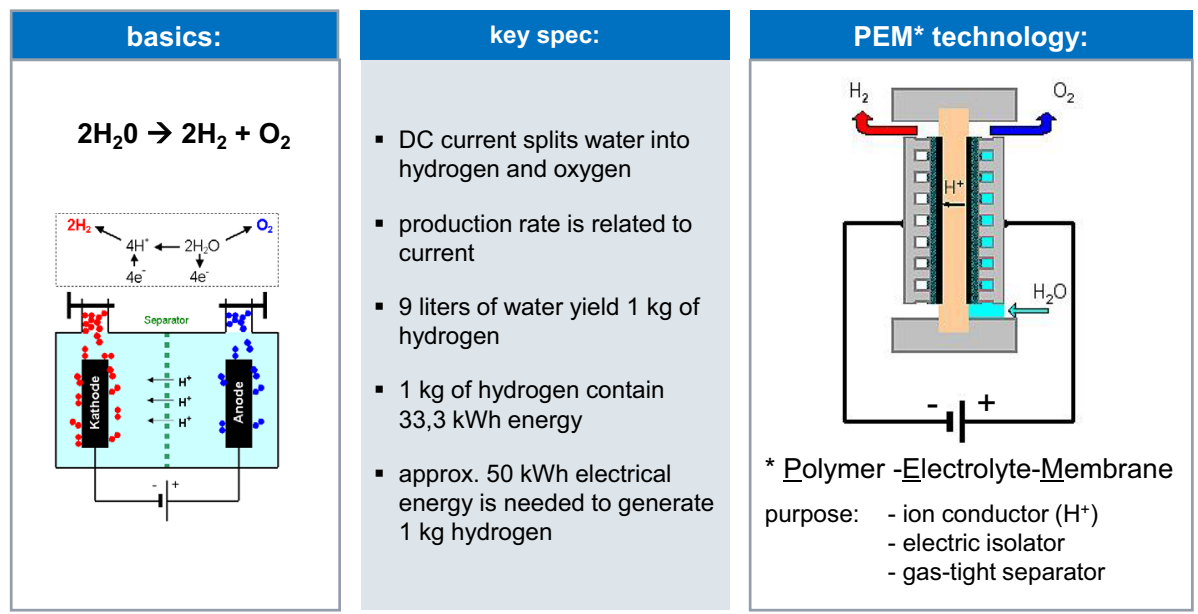

Fig. 7. - Large-scale storage options for hydrogen (source: T. Bielmeier, Siemens).

flame speed of hydrogen, which requires a specific adaptation of the burner for pure hydrogen. Gas turbines with a $\mathrm{H}_{2}$-capability up to $100 \%$ are under development. They will be required in case of a future zero-emission society.

At present, the business case of re-electrification is not economic without legal regulation. Generated hydrogen competes with the price of natural gas, as the value is determined by the heating value only. Competitiveness of electrolytic hydrogen significantly increases in those applications in which hydrogen is needed essentially in the process. Depending on the scale of conventional hydrogen production related generation costs are in a range between 1.4 and 5 USD per kg. The agreement of car manufacturers, oil industry and gas suppliers agreed to sell hydrogen to end users at a price below $10 \mathrm{USD} / \mathrm{kg}$ based on delivery costs of $4-5 \mathrm{USD} / \mathrm{kg}$ (fig. 8 ). Moreover, the existing huge demand of hydrogen in refineries will be estimated adequate to the admixing of

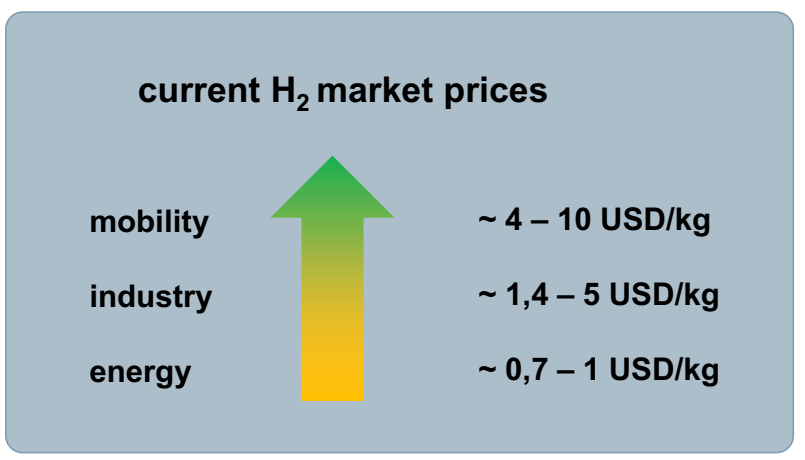

Fig. 8. - Value of hydrogen in different markets. 


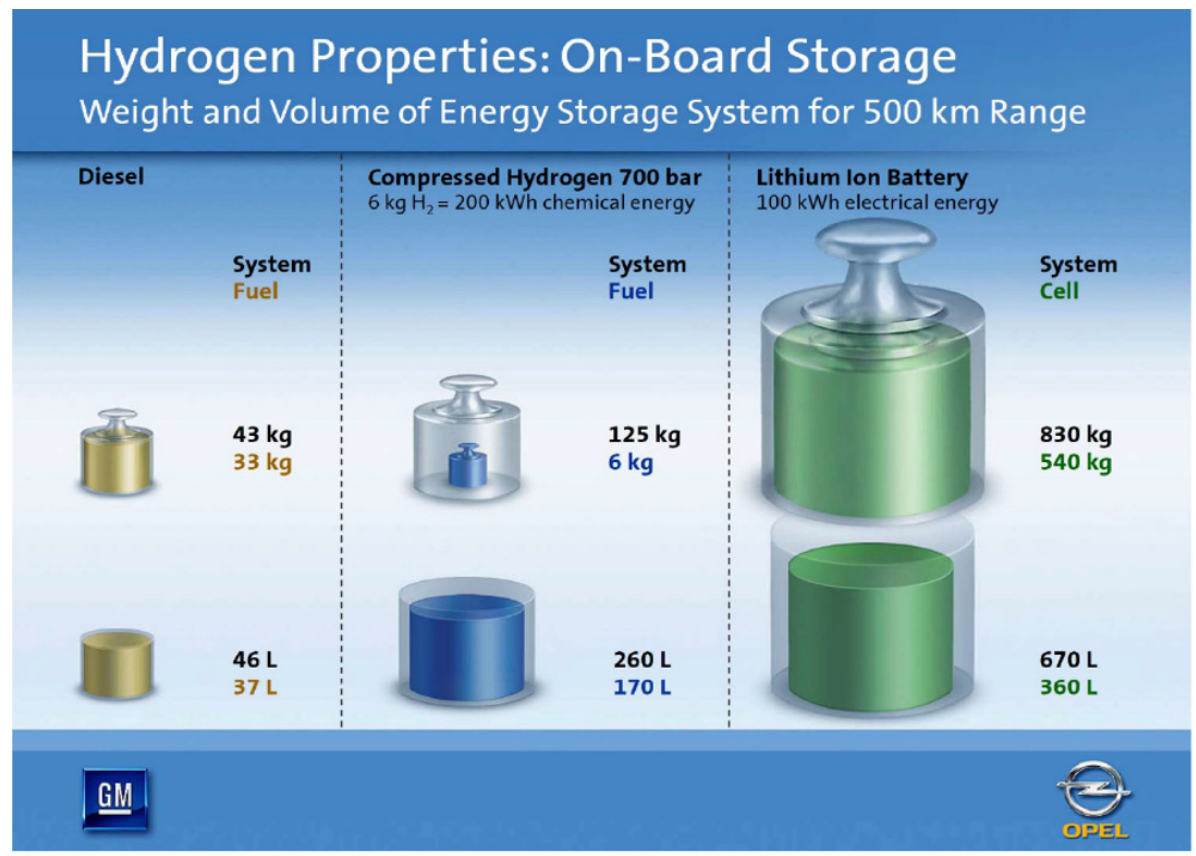

Fig. 9. - Weight and volume of onboard fuels, needed for a driving range of $500 \mathrm{~km}$ (source: R.v. Helmholt, General Motors/Opel).

bioethanol. This means, no additional taxes or fees are required to enable $\mathrm{CO}_{2}$ savings even with existing car fleets and conventional fuels.

The idea of green fuels was already described in 1870 by Jules Verne: "Water is the coal of the future. The energy of tomorrow is water, broken down into hydrogen and oxygen using electricity. These elements will secure the earth's power supply for an indefinite period". This vision is worth to consider not only from the point of $\mathrm{CO}_{2}$ reduction, but also from the viewpoint of sustainability.

The vision of eCars started already in the time around 1900. There was a strong head to head race between battery cars and combustion engines. Battery technology was well established at that time.

In the recent years, driven by environmental and sustainability argumentation, all major car manufactures are stepwise replacing their product portfolio with electric drive options. The first step on that route was to recuperate braking energy (mild hybrids). The second step was the development of plug-in hybrids with the capability to charge the battery externally. In the last years pure eCars are re-entering the roads. Startups like "Tesla" are challenging the established players. The emerging new market, but mainly to prevent impending penalties when hitting defined $\mathrm{CO}_{2}$-targets with their fleets, urges all major manufacturer to sell full-EVs in increasing numbers.

A retarding fact is that batteries suffer from their notably lower energy density compared to gasoline or diesel. As a result their range of operation is much shorter compared 


\section{Powertrain strategy}

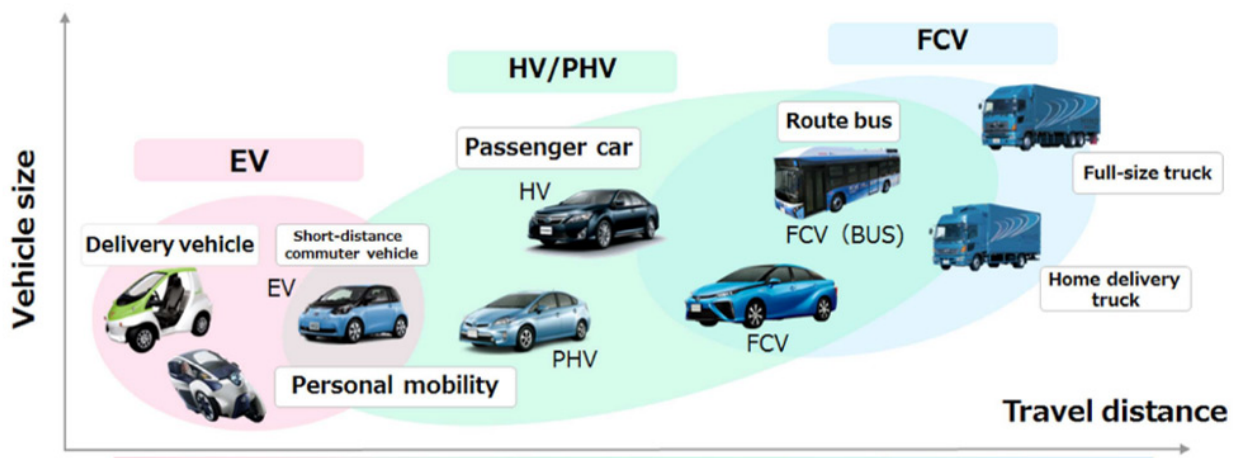

Fuel Electricity Gasoline, diesel, biofuels, CNG, synthetic fuels, etc. Hydrogen

\section{EV: Short-distance, HV \& PHV: Wide-use,} FCV: Medium-to-long distance

7

TOYOTA

Fig. 10. - Powertrain strategy as a function of vehicle size and travel distance (source: A. Fuchs, Toyota Motors).

to existing cars. Hydrogen instead does not reach the energy density of diesel, but from that point of view is much better than lithium batteries. On the other hand storage of this fugitive gas is more sophisticated (fig. 9).

It is obvious that there is a new competition between two zero-emission technologies, i.e. between batteries and fuel cells. Battery systems are simple but suffer from a restricted range of operation. Fuel cell systems provide a high driving range but are more complex and require a sufficient refueling logistic. Therefore, all major car manufacturers follow battery and fuel cell systems in parallel, as both technologies have clear pro's and con's. The right choice will be derived from two main criteria: vehicle size and travel distance (fig. 10).

As a very simple thumb rule for the end user to select the powertrain most suited for his individual needs the following indication can be given:

- small cars and short distances $\rightarrow$ batteries;

- big cars, busses and trucks, long-distance traffic $\rightarrow$ fuel cells.

An additional decision criterion is the time required for refueling or charging. A typical charging time of $30 \mathrm{~min}$ (for approximately $80 \%$ state of charge) of batteries 


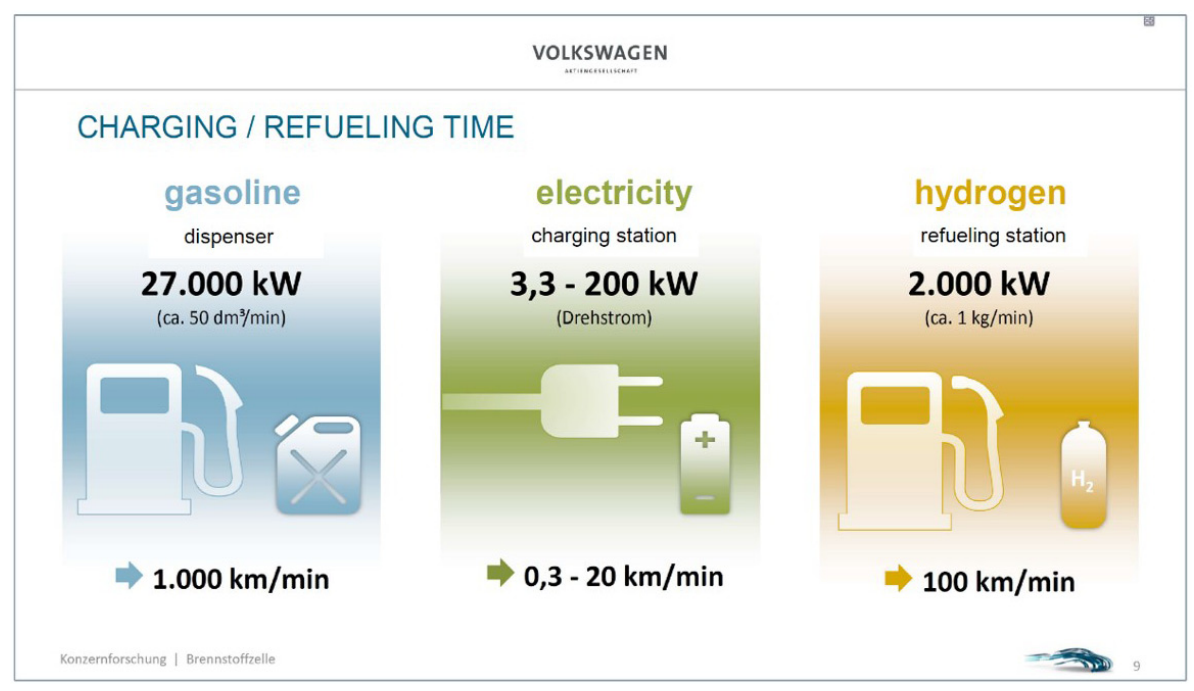

Fig. 11. - Charging characteristics of eCars compared to conventional cars with combustion engines (source: F. Seyfried, Volkswagen).

requires extended acceptance by the driver. Quick-charging capabilities of batteries can be improved but only with losses in energy density. Moreover, battery quick-charging will challenge the grid frequency (end user driven). In general, there is no alternative to gasoline regarding refueling time but hydrogen comes close (fig. 11).

Summarizing, both electric systems will have their reason to co-exist. Today, batteries still have a technical lead compared to fuel cells from the viewpoint of mass production. But fuel cells, mainly suffering from higher material and production costs rapidly step forward.

Due to the higher costs of both eCar options compared to the internal combustion engines (ICEs; optimized over more than 100 years) legal directives will remain necessary for a given time to enforce the technology change. Several manufacturers state that pure ICEs will not be produced any longer and hybrids will be the minimum standard in their next-years portfolio.

A fundamental change in technology always evolves new players, not visible before. For instance, China (fig. 12) - far behind other countries in ICE technology - strategically decided to stress the disruptive electric route:

- in battery technology China improved very fast in the last two decades;

- fuel cell propulsion is aggressively pushed in the last decade.

Hydrogen refueling stations are still the bottleneck but roll out continuously. Car manufacturers, oil and gas companies and other big parties associated in the " $\mathrm{H}_{2}$ Mobility" to organize the roll out of $\mathrm{H}_{2}$ refueling stations. Trains, busses and other logistic 


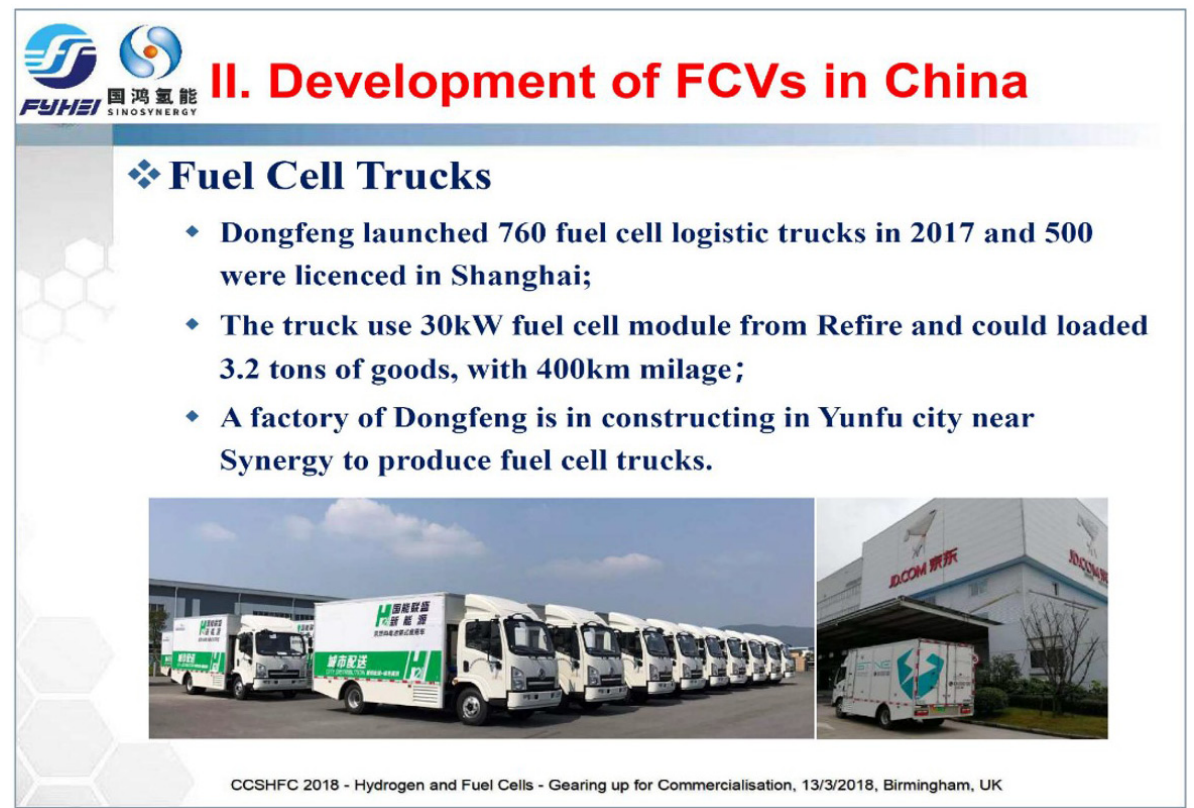

Fig. 12. - Selected example (out of many) from China's huge engagement in clean transportation.

vehicles will additionally stimulate the penetration of a $\mathrm{H}_{2}$ logistic as they are usually fueled in their home base or in hubs.

It is clear that battery technology as well will provide progress in the future. However, quick charging will remain a challenge. A systematic improvement is possible, but then with notable cuts in energy density. Relevant properties as "energy density", "cycle life", "quick charging", "safety" and "costs" must be seriously balanced (fig. 13).

Meanwhile all car manufacturers committed themselves to environmental targets. Zero- $\mathrm{CO}_{2}$ targets will be extended to the whole cycle life of a car. This means that all plant operations like production, water usage, recycling, etc. will be included in the zero targets as a total environment view. For instance, production alone contributes with roughly $20 \%$ to the total $\mathrm{CO}_{2}$-emissions in the life of a car.

A new trend in car technology - not directly linked with emission reduction but nevertheless important for increasing traffic density - is autonomous driving. Hereby, laser-based LIDAR (light detection and ranging) is the key for car autonomy. LIDAR delivers information of direction and speed of other moving objects in a much higher resolution than radar-based systems. In addition, connection with other cars will allow the detection of shadowed road users. Secure and ultra-fast communication will be essential. Related concepts are available. However, they have to be established and standardized.

The targets regarding failure safety are very high. Target numbers for fatal errors are $<10^{-8}$ per hour (while statistically a human on average causes around $10^{-3}$ fatal errors per hour driving). Nevertheless, the major retarding problem will be to clarify legal responsibilities in case of an accident. 


\section{Catch 22 for automotive batteries}

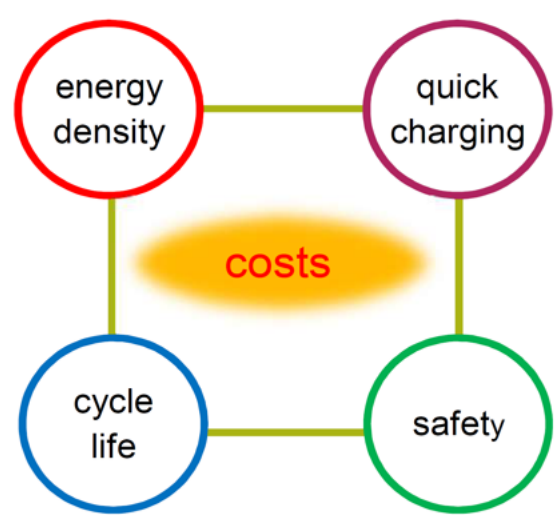

Fig. 13. - Required properties of car batteries are in conflict with each other.

Heavy duty transport also strongly contributes to $\mathrm{CO}_{2}$ emissions. Here, in some places electrified tracks with catenary operation have been built. This is an interesting concept for routes which are well defined and frequently operated. Electric vehicles are operated successfully since decades e.g. for mining vehicles but also for public transport. In this case the installation costs for catenaries are overcompensated by the lower operational costs of electric motors compared to ICEs. In addition, a local zero emission operation is realized.

The surface freight density of large goods will further increase in the next decades (fig. 14). As a special characteristic a high percentage of related emissions is concen-
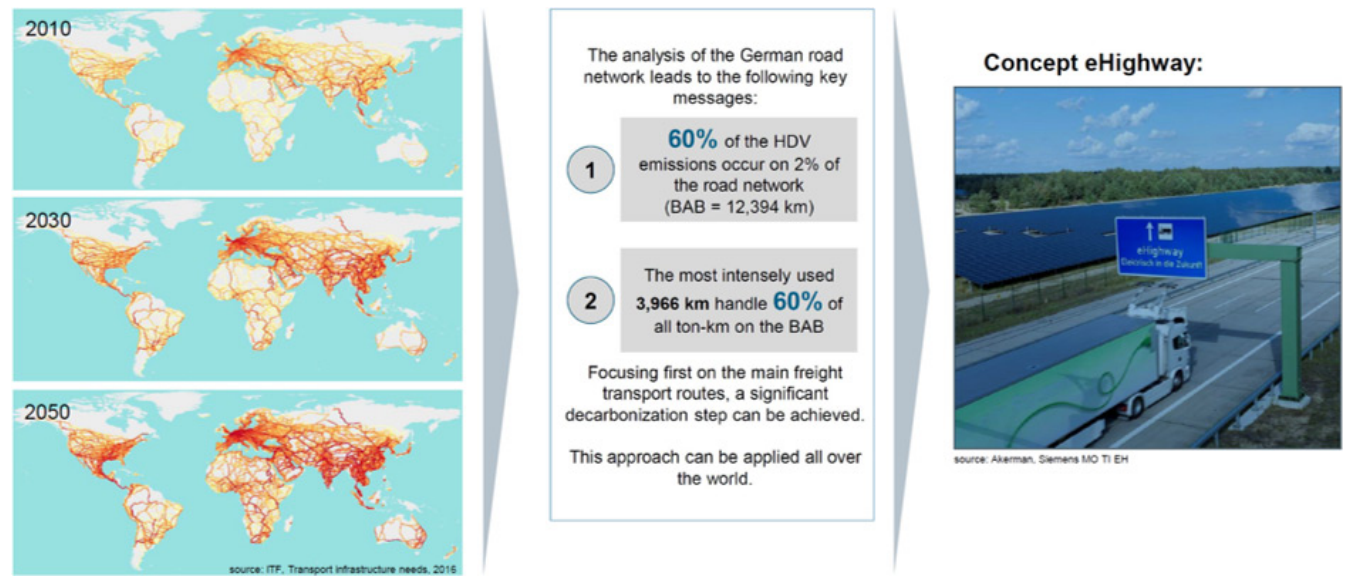

Fig. 14. - The surface freight will notably increase in the next decades. The "eHighway" concept for frequently used routes will lower $\mathrm{CO}_{2}$ emissions. 


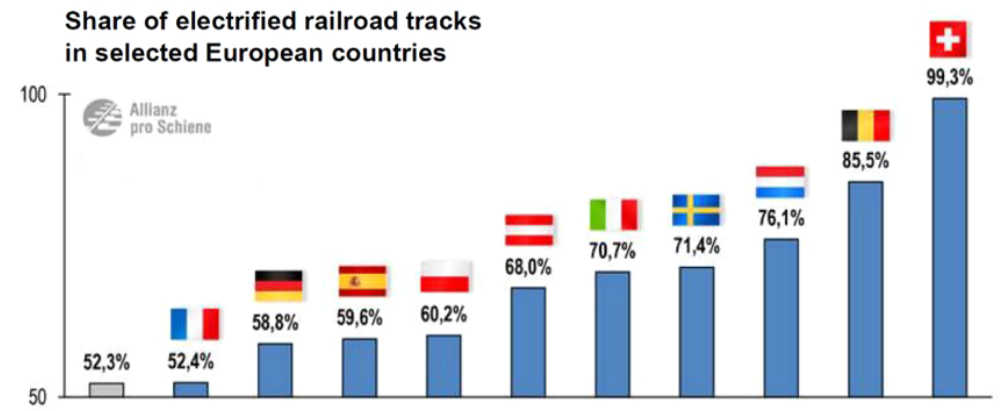

Fig. 15. - Share of electrified railroad tracks in selected European countries; data basis 2010. Source: Allianz pro Schiene (2012).

trated on only very few roads (for example, in Germany, the most intensively used $4000 \mathrm{~km}$ motorway handles $60 \%$ of all ton-km). This is the basis of the idea "eHighway". Here, heavy duty trucks are equipped with a catenary driving on an electrified road lane. Projects to evaluate this concept are currently running in Germany, USA and Sweden. Tracks have been selected e.g. in the ports of Los Angeles or the connection of an industrial area to the seaport.

Rail-bound traffic started its electrification already in 1881. The first demonstrator of an electric locomotive was even shown in 1879. At that time the method of electrification was still unclear. Several demonstrators were built to benchmark DC, AC and 3phase electricity concepts. In addition, it was undecided at that time how to realize the power supply: overhead contact lines or current bars. It is obvious that the advantages of overhead electrification made the race. Meanwhile, roughly $52 \%$ of all European rails are electrified (fig. 15).

Standard solution for non-electrified railroad propulsion are diesel modules. However, their operation causes notable service and maintenance costs in addition to their intrinsic $\mathrm{CO}_{2}$-footprint. A replacement of the diesel engine by fuel cells was proposed and even tested in the 1990s, but the concept studies never reached product status (insufficient reliability, high costs, lacking $\mathrm{H}_{2}$-infrastructure).

Since that time, driven by car industry developments, a notable progress in regarding reliability and costs of fuel cells has been achieved. Alstom realized a new fuel cell powered prototype of a regional train, which is under successful test since 2018 (fig. 16). Meanwhile, also other manufacturers initiated related plans and developments. $\mathrm{H}_{2}$ logistic and fueling will happen via hubs - much easier to realize than for road traffic.

The environmental impact of sea transport was ignored for a long time. The importance is extreme, as roughly $90 \%$ of all global goods transport is conducted via ships. It is not only the exhaust of $10^{9}$ tons $\mathrm{CO}_{2}$ per year but the very severe amounts of $\mathrm{SO}_{2}, \mathrm{NO}_{x}$ and particulates. Ships contribute roughly $3 \%$ of human made $\mathrm{CO}_{2}$ to global emissions, but $15 \%$ of $\mathrm{NO}_{x}$ and $13 \%$ of $\mathrm{SO}_{2}$.

The engines burn heavy and residual oil as fuel (consistency like tar), which con- 


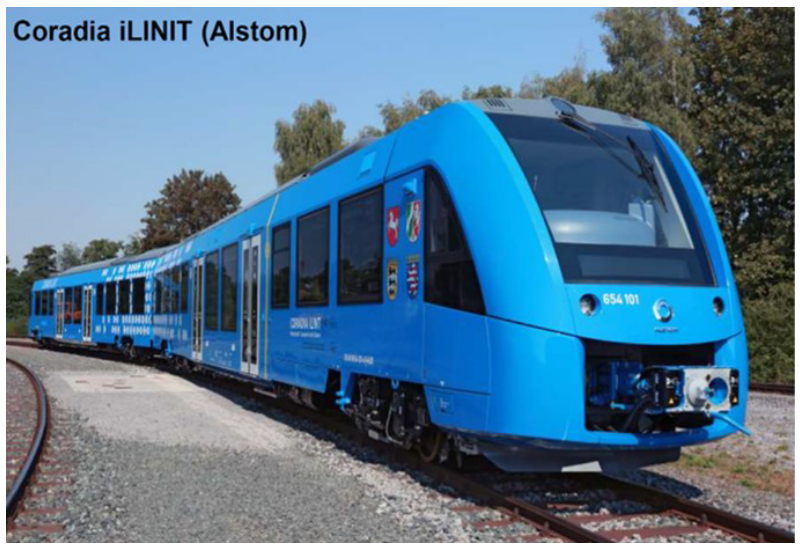

Fig. 16. - Prototype of a fuel cell powered lightweight train made by Alstom. Source: https:// www.alstom.com/de/press-releases-news/2018/9/weltpremiere-alstoms-wasserstoffzuege.

tains up to $3.5 \%$ sulfur (for comparison: car fuel $<10 \mathrm{ppm}$ ) and approximately $2.5 \%$ unburnable substances (new fuel directives announced for 2020).

Solutions are viable, e.g. by using LNG. For short distances (e.g., ferries) battery or fuel cell powered ships are already in operation or under construction (fig. 17).

Airborne traffic will more than double in the next three decades. Even at present there are approximately 100000 flights per day (small private planes not considered) leading to $\mathrm{CO}_{2}$ emissions of approximately 1000 Mio tons per year.

The International Air Transport Association (IATA) has settled concrete plans for

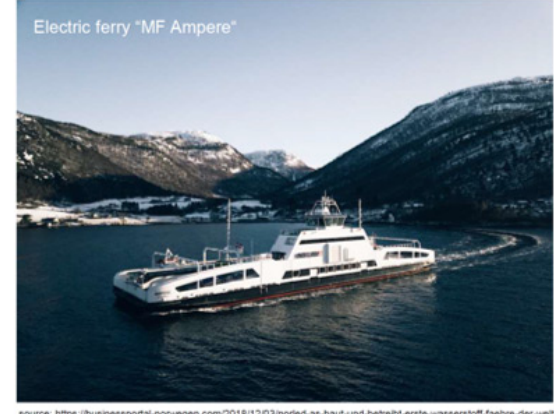

- operated by Norled in Sognedfjord, Norway

- battery powered

- under operation since 2014
- New fuel directive for ship fuels announced for 2020

- LNG will notable reduce emissions (significantly $\mathrm{SO}_{\mathrm{x}}$ and particulates)

- Battery powered ships will be a solution for short distances (e.g. ferries)

- First installations with hydrogen powered systems already decided e.g by Norled, Norway: start of operation planned 04/2021

Fig. 17. - Zero-emission ferry, operated in Norway. Source: https://businessportalnorwegen. com/2018/12/03/norled-as-baut-und-betreibt-erste-wasserstoff-faehre-derwelt. 


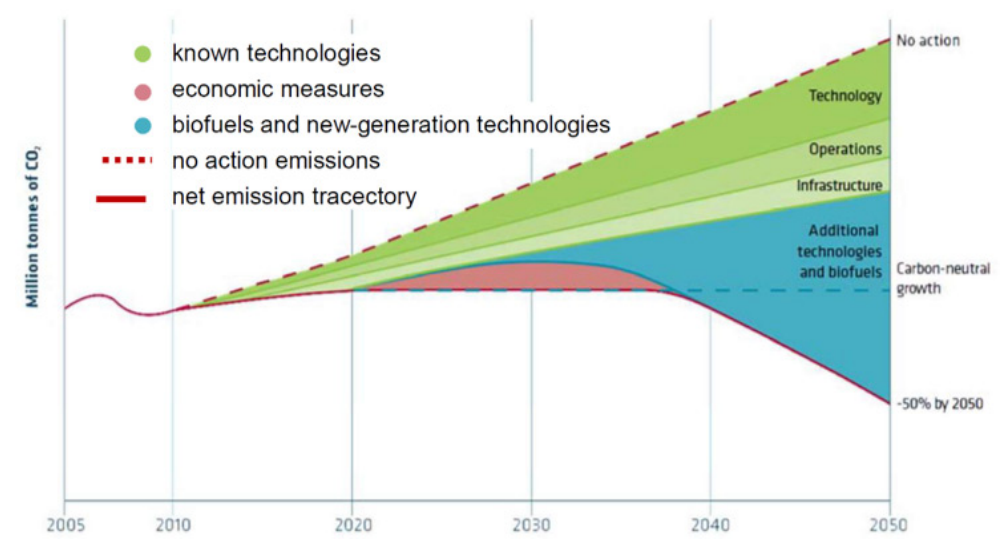

Fig. 18. - $\mathrm{CO}_{2}$-reduction targets of IATA including estimates of effect by individual measures. Source: ATAG 2013; IATA Annual Review 2015.

$\mathrm{CO}_{2}$ reduction and commits to cut $\mathrm{CO}_{2}$ emissions to $50 \%$ by the year 2050 (fig. 18). This can only be achieved by "additional" technologies supplementing an increased use of biofuels. Batteries will be not the right choice though electric motors provide better efficiency than air turbines. The most crucial bottleneck will remain the energy density of the electrochemical storage systems, which is nearly 2 orders of magnitude below kerosene (an Airbus 380 with a max take-off weight of $560 \mathrm{t}$ holds up to $320 \mathrm{t}$ of kerosene). So, in the most positive case, electric aircrafts may be a solution for short-distance passenger transportation. Battery-operated flights will not be able to contribute notably to $\mathrm{CO}_{2}$ reduction in aviation.

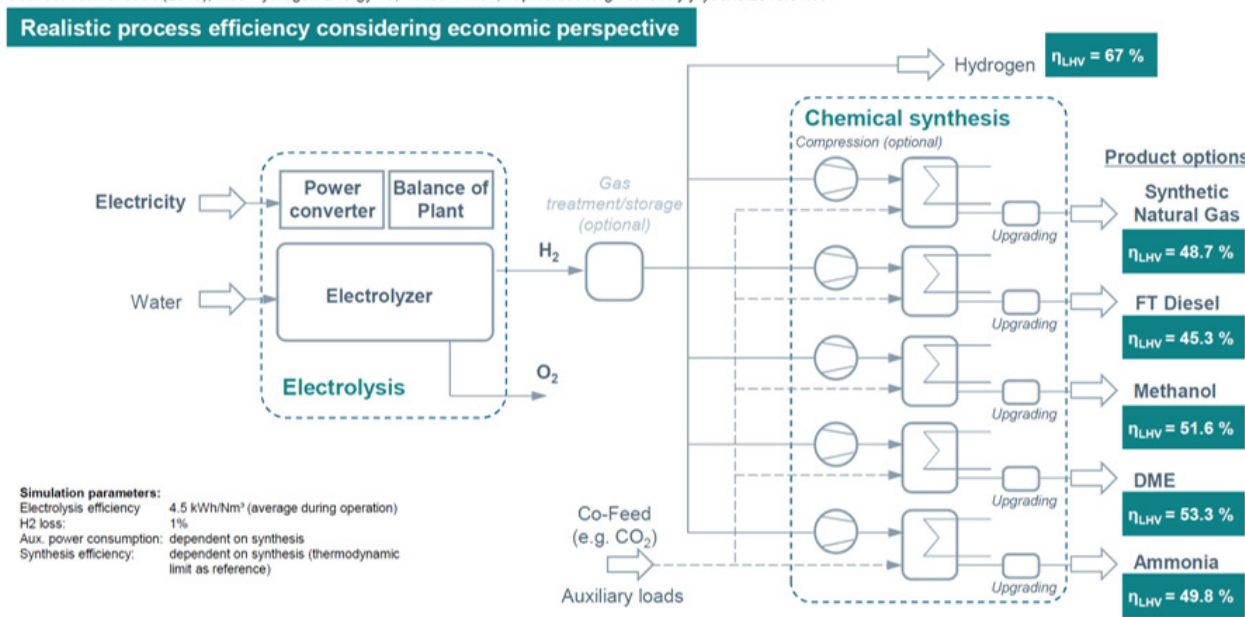

Fig. 19. - Different production routes of conceivable synthetic fuels (eFuels) including efficiencies for its production. Source: A. Tremel, Siemens. 
At present, biomass-based additives are used. This is a subsidized market and will be allowed only to a defined limit. Synthetic fuels provide the most promising specs regarding volumetric and gravimetric energy density. They can be produced out of green hydrogen and $\mathrm{CO}_{2}$ (fig. 19). However, the required quantities are enormous (today approximately $300 \mathrm{Mio}^{3}$ jet fuel).

Synthetic fuels are technically viable, however production costs are the main obstacle and require cheap electricity. The dominant cost factor in the production of electricitybased fuels (e-fuels) is the electricity price. Based on European electricity price levels e-fuels will have a serious cost problem. But there are regions in the world where green electricity is very cheap. Related strategies are under development.

\section{Summary in a nutshell}

- Sector coupling will be essential to reach national and global $\mathrm{CO}_{2}$ reduction targets.

- The required extension and over-installation of renewables will require storage capacities in the TWh-range.

- Hydrogen via Power-to-Gas is the most promising enabler to drive the abovementioned de-fossilization.

- Electrolyzer plants will be required in the GW-scale. Scale-up is ongoing rapidly. Material resources are not considered as retarding bottleneck.

- Global companies, like Siemens, are preparing to provide electrolyzer systems and related technologies in the required power range and volume.

- The future of road traffic will be electric. Batteries and fuel cells will be complementary.

- Autonomous driving is on the way. Legal responsibilities have to be clarified.

- Progress in battery development will be marginal. Higher energy density always has to be balanced with safety and cycle life.

- Aviation and long-distance sea transport still will need an "energy carrier" with an energy density comparable to oil-based fuels.

- Hydrogen will be the future energy vector. E-fuels will be the approach when high volumetric and gravimetric energy density is required.

- Countries with very low renewable energy costs are preparing for the future business with hydrogen and e-fuels. 